\title{
Practical Tips for Teaching Postgraduate Residents Continuous Quality Improvement
}

\author{
Roger Y. Wong* and J. Mark Roberts
}

\author{
Postgraduate Medical Education, Department of Medicine, University of British Columbia, Vancouver, British Colum- \\ bia, Canada
}

\begin{abstract}
Background: Continuous quality improvement (CQI) in health care involves changes that result in better clinical and process outcomes. Accreditation bodies are mandating postgraduate educational programs to teach CQI among residents, although their baseline knowledge and experience vary tremendously. There is no single effective method to teach CQI.

Aim: To develop a comprehensive CQI curriculum for residents.

Work Done: This article describes the experiences of developing a CQI curriculum for trainees working in the university internal medicine residency program in Vancouver, British Columbia, Canada. We report the key elements for other educational programs interested in developing similar curricula.

Conclusions: A formal CQI curriculum that teaches basic theory and includes an independent, focused project is a useful model, and broad dissemination is advisable. There should be protected time for teaching and learning, using interactive and case-based methodology. Communication and collaboration skills can be emphasized. Longitudinal and face to face mentoring are helpful. An open forum on CQI can raise awareness, and a separate assessment and reward system can motivate residents. Further training opportunities for faculty and interested residents should be available. Hospital staff and departmental support is essential. The CQI curriculum needs to undergo continuous improvement itself.
\end{abstract}

\section{INTRODUCTION}

Continuous quality improvement (CQI) in health care has gained much popularity and significance in the last decade. It refers to a worldwide movement in improving patient safety and reducing medical errors, while creating a system-based approach of managing process changes to optimize clinical care delivery [1-3]. Although continuous professional development (CPD) programs on CQI are available, many practicing physicians find these challenging as they have no or little prior exposure to CQI and are in fact too busy to learn it anew alongside with active clinical practices. In fact, accreditation bodies for postgraduate medical education programs are now mandating CQI being properly taught as a core competency [4-6]. There is no single proven effective way to teach CQI. Rather, different teaching models exist, including those with predominant theoretical constructs [7], predominant practical focus $[8,9]$, and combined theory and practice [10], Conventional wisdom in CQI encourages clinicians to both learn the fundamental theories and engage actively in authentic clinical projects [11], although the translation of these educational principles into postgraduate residency training is not well documented. We recently developed an innovative CQI curriculum for junior internal medicine residents $[12,13]$. This article highlights some tips as a guide to other medical educators who wish to develop similar curriculum for their postgraduate training programs.

*Address correspondence to this author at the 7153 - 2775 Laurel Street, Vancouver, BC, Canada, V5Z 1M9; Tel: 604-875-4826; Fax: 604-8755696; E-mail: rymwong@interchange.ubc.ca

\section{TIP 1}

\section{Create a Formal Curriculum}

For many residents, CQI processes and tools are novel concepts and deserve proper teaching just like any other medical content. The creation of a formal curriculum allows for development of focussed educational objectives (which in turn translate into specific CQI-related competencies), allotment of scheduled teaching time, and formulation of detailed lesson plans and feasible timelines. Although CQI concepts may be taught in conjunction with other clinical knowledge and skills during hospital or ambulatory rotations (informal curriculum), the teaching experience on CQI per se is often diluted and less focussed. When building the formal CQI curriculum, it should be done within the existing curriculum construct (for instance, incorporate formal teaching during academic full or half days). Existing teaching models in the literature can provide a useful starting point, and customized learning needs assessment can originate from educators, residents, and CQI data from local hospitals and/or health regions, etc. The latter is especially helpful in adding relevance and legitimacy to the curriculum. Once the curriculum is set, there should be a clear communication plan with residents, with expectations clearly outlined from the beginning of residency. In fact, we suggest discussing the curriculum briefly during the pre-residency recruitment phase and in more detail during the post-recruitment residency orientation as well as subsequent group discussions. 


\section{TIP 2}

\section{Teach Basic Theory and Include an Independent, Small and Focused Project}

Our experience working with first-year medical residents reveals that we have to teach CQI from the very basic, as most of them report minimal or no prior knowledge and experience. This might change in the future if undergraduate medical schools begin to teach CQI, although this is not widespread for the time being. Fundamental concepts that need to be taught explicitly include: the differences between quality improvement and quality assurance, model for improvement, team composition, aim statement, process flowcharting, selection of indicators, change management, sampling techniques, types of variation, and CQI tool boxes [11]. The ideal curriculum can also include an independent CQI project, which provides residents the opportunity to apply what they have learned in the real clinical setting. The project may involve a written report, a self-reflection essay to be included in the resident's learning portfolio [6], or an authentic CQI project that involves at least 1 plan-do-study-act cycle (PDSA). Our experience suggests the latter done in a resident team setting, together with a written CQI abstract, appears to be a welcoming combination for residents. In any event, educators need to resist the temptation of being directive in project selection, for residents enjoy the freedom to choose projects that are realistic and relevant to them. If necessary, especially with more controversial topics, educators may wish to consult with local hospital, health regional administration and/or legal support staff.

The importance of seeing a CQI project through from start to finish should be emphasized. Inexperienced, but enthusiastic, residents often want to attempt large projects that produce statistically significant results. Similarly, residents should not be discouraged by unexpected or negative results. Given the time constraints within the curriculum, it is much more important to emphasize completion of a small, doable, often pilot project. Residents who wish to complete larger publishable results should be encouraged to do so through research electives.

\section{TIP 3}

\section{Use Interactive and Case-Based Teaching}

When teaching the formal CQI curriculum, a variety of teaching methods can be used, including didactic lectures, interactive workshops, and case-based teaching. We prefer to deploy all of the above. Lectures are useful to teach theories and core concepts, interactive workshops can facilitate team building and group learning, and case-based teaching helps to illustrate the clinical application of book knowledge [14]. We use cases with content that is familiar to the residents (that is, from the same clinical field), and build in ample time for reflection, discussion and sharing. We also recruit past residents who have graduated from the curriculum to help us teach new resident learners. The resident teachers can be effective in sharing their perspectives on CQI (both before and after taking the curriculum), as well as reassuring their junior counterparts that CQI is a useful and feasible skill to learn.

\section{TIP 4}

\section{Ensure Adequate Time for Teaching and Learning}

A common pitfall when teaching CQI is not providing adequate protected time. We therefore decided to deliver the curriculum longitudinally over 15 months (that is, we start teaching CQI theory in September and October during first year residency, and residents conduct their projects until November in second year residency). We set aside protected time ( 2 full academic half days, plus 1 hour per week subsequently during academic half days the rest of the time) when residents are excused from clinical duties to partake in CQI activities. While educational programs would want this, we have to remember that CQI should become part of the culture and therefore integrate with regular clinical activities. For this reason, in some institutions, the CQI curriculum is delivered over a clinical rotation block [10]. This arrangement helps to emphasize that CQI is not something that one does only when one has extra time.

\section{TIP 5}

\section{Integrate Other Important Skills Relevant to CQI}

In the business sector where CQI first emerged, effective communication and collaboration skills are key elements for the success of CQI [15]. The health care setting is no exception. When teaching residents CQI, educators can use the opportunity to teach models of team building and effective communication. Examples of useful teaching resources can be found in the literature on human resources and organizational behavior $[16,17]$. Standardized communication training frameworks customized for the health care setting can be especially helpful to cover communication competencies that are useful in CQI $[18,19]$. Educators can also provide residents basic contact information on key opinion leaders and stakeholders (such as health record departments, CQI departments, etc.) that facilitate resident completion of their independent projects.

\section{TIP 6}

\section{Provide Longitudinal and Face to Face Mentoring}

Given different CQI teams plan and complete tasks at different paces, it is crucial for educators to ensure all independent project teams reach important milestones at various time points. Longitudinal follow up on a formal basis (such as through a series of organized tutorial sessions) is essential to check if teams are on track, and more importantly, allows for the opportunity to offer additional assistance for teams that are behind. During the tutorials, there should be clearly laid out expectations of residents in terms of achieving key CQI milestones (for instance, completion of team formation, selection of aim, conduction of situation analysis, initiation of data collection and analysis, formatting and presentation of findings, etc.) Residents are encouraged to ask projectrelated questions, which in turn facilitate group discussion and collective problem solving skills. We suggest regular face to face sessions to optimize the mentoring experience [20], which can build upon ongoing and continuous informal email and personal communications. When providing feedback, educators can reflect on the principles of effective feedback [21]. 


\section{TIP 7}

\section{Raise Awareness in an Open Forum}

While CQI educational programs may improve knowledge and/or attitude among residents [10], it is equally (if not more) important to demonstrate to residents the impact on clinical practice. There are various methods to illustrate this, such as through practice audits, portfolios, and self assessments [22]. We recently created a conference style forum to showcase the resident independent projects at an annual departmental Resident Day on QI, whereby all teams deliver podium presentations followed by questions and answers [12]. This forum is highly promoted and well attended by residents, key stakeholders from the local hospitals and health regions. The junior residents are encouraged to role model after their senior counterparts before starting their own projects. The forum also includes a keynote presentation by an external CQI expert, which further enhances the educational experience for both residents and faculty. The selection of the keynote speaker deserves careful attention, as our experience suggests that a dynamic, enthusiastic and realistic speaker can have lasting impact in motivating residents through their CQI projects.

\section{TIP 8}

\section{Create a CQI Assessment and Reward System}

We choose to make our CQI curriculum mandatory for all residents to maximize the educational impact. While there are CQI teaching models that build on elective experiences [10], we are concerned that few residents will subscribe to the elective as they may not know what they do not know. The mandatory requirement also helps to motivate residents as they know they will be assessed based on their CQI competencies, which forms one of the promotion requirements. Assessment of CQI is not a simple task. We have adopted a multi-faceted assessment system, which comprises a standardized QI knowledge assessment test, QI self assessment proficiency, and a balanced score sheet for the team project. The first 2 assessment tools have been previously validated [10], and the latter is developed locally and currently under further improvement based on published guidelines [23]. Since the implementation of our CQI curriculum, we have also created a CQI award structure on a competition basis to reward resident teams who excel in their clinical projects. The awards include cash prizes and commemorative certificates, which are well received by residents. We also emphasize to residents that their CQI achievements will be documented in their program director reference letters during their applications to subspecialty fellowship programs.

\section{TIP 9}

\section{Offer Advanced Training Opportunities for Faculty and Interested Residents}

One of the biggest challenges in developing and implementing a successful CQI curriculum is the paucity of trained medical faculty who are comfortable in delivering the material. This is likely a result of multiple factors, including sub-optimal knowledge and/or interest [24]. Short term strategies to address the faculty shortage include crossdepartmental recruitment of teachers and/or liaison with non- medical personnel (for instance, teachers from business schools). Long term strategies include providing "train the trainer" courses at the university or national level, preferably multiple times during the year to capture the largest possible number of faculty. These may involve newer technologies such as Internet webcasts. Senior residents, subspecialty fellows and junior faculty members should be encouraged and supported in obtaining additional expertise in CQI. Obviously, support from the teaching department and university is essential. Funding and remuneration is another issue, as it costs money to organize faculty development sessions and pay the trainers.

For residents who express the interest in receiving further CQI training beyond what we teach in the residency curriculum, there should be other opportunities for advanced training. Although specialized programs such as 1 or 2-year fellowships in CQI exist, they may not be available at all jurisdictions. Portable or remote learning courses in CQI represent a viable alternative [11]. Residents need to understand that with appropriate training and experience, CQI may become a career path for some. There is also increasing recognition of CQI work in the medical literature [23].

\section{TIP 10}

\section{Share the Teaching Experience with Your Colleagues}

CQI is difficult to do, and equally difficult to teach properly. As many postgraduate programs are mandated to teach CQI, it makes sense to disseminate and share curriculum materials at the national and/or international levels, provided local CQI needs can be accommodated and incorporated into the curriculum. Support from accreditation bodies is essential. For instance, educational workshops and symposia organized to review big picture issues on CQI teaching can not only create momentum but also help educators plan their teaching endeavours by learning from each other. In addition, success stories can be shared on Internet websites [11]. Our experience has seen expansion of the CQI curriculum, which is being implemented in other departments within our university, as well as to various departments in other universities across Canada.

\section{TIP 11}

\section{Engage Local Hospital CQI Staff and Departments}

Most hospitals have administrative staffs that have significant theoretical and practical knowledge in Quality Improvement. They can be very helpful in providing didactic sessions, mentoring small groups and providing infrastructure support for data acquisition and analysis. We have found our QI departments to enthusiastically embrace this curriculum and projects. We have engaged supervisors as adjudicators for our Resident Day on QI. In addition, our hospital administrations have been solicited and have provided financial support for our Resident Day on QI.

\section{TIP 12}

\section{Apply CQI Principles to the CQI Curriculum}

Last but not least, the CQI curriculum should be subjected to the same model for improvement similar to any other clinical CQI initiatives. These include proper evalua- 
tions, PDSA rapid cycling, and change management. Measurement instruments to evaluate the impact of the curriculum should be selected carefully, ideally standardized, validated and reliable (10). Ongoing feedback from residents should be collected continuously. It is helpful to anticipate challenges proactively, and develop strategies to address them accordingly. There should be recognition of the need for ongoing changes. Our experience is a vivid illustration: the lecture and tutorial materials of our curriculum undergo substantial revisions every year based on feedback from the previous year's delivery.

\section{CONCLUSION}

Overall, teaching postgraduate residents CQI is a new and rather complex educational intervention. The principles that we highlight are helpful on the broad level (Table 1), although specific details for local programs will vary based on individual resident and clinical program needs. We hope this would be a fun experience that empowers and motivates residents to pursue more CQI activities during their career lifetime.

Table 1. Key Elements of Teaching Residents Continuous Quality Improvement

\begin{tabular}{|c|}
\hline Practice Points \\
\hline $\begin{array}{l}\text { - The formal CQI curriculum should include teaching basic theory } \\
\text { and an independent project. Emphasize process not results. }\end{array}$ \\
\hline $\begin{array}{l}\text { - There should be adequate and dedicated protected time for teaching } \\
\text { and learning, using interactive and case-based methodology. }\end{array}$ \\
\hline $\begin{array}{l}\text { - An open forum on CQI can raise awareness, and a separate assess- } \\
\text { ment and reward system can motivate residents. }\end{array}$ \\
\hline $\begin{array}{l}\text { Engage help and support from other departments, faculties and } \\
\text { hospital administrative staff. }\end{array}$ \\
\hline $\begin{array}{l}\text { - The CQI curriculum needs to undergo continuous improvement } \\
\text { itself, and when doing so, share your experience. }\end{array}$ \\
\hline
\end{tabular}

\section{ACKNOWLEDGEMENT}

Funding support is provided by a 2006 Royal College of Physicians and Surgeons of Canada/Associated Medical Services CanMEDS Research and Development Grant.

\section{REFERENCES}

[1] Berwick DM. A primer on leading the improvement of systems. Br Med J 1996; 312: 619-22.

[2] Curtiss FR. Crossing the quality chasm - Incremental change through clinical practice guidelines (CPGs). J Manage Care Pharm 2002; 8(5): 400- 2.

[3] College of Family Physicians of Canada. Family Medicine in Canada: vision for the future. Online information available at http://www.cfpc.ca/local/files/Communications/Health\%20Policy/
FAMILY_MEDICINE_IN_CANADA_English.pdf (accessed on March 9, 2008), 2004.

[4] Frank JR, (Ed). The CanMEDS 2005 physicians competency framework. Better standards. Better physicians. Better care. Ottawa: The Royal College of Physicians and Surgeons of Canada 2005.

[5] College of Family Physicians of Canada. Standards for accreditation of residency training programs: Family Medicine, Emergency Medicine, Enhanced Skills, Palliative Medicine. Online information available at http://www.cfpc.ca/local/files/Education/ Red\%20Book\%20Sept.\%202006\%20English.pdf (accessed on March 9, 2008), 2006.

[6] Accreditation Council for Graduate Medical Education. Advancing education in practice-based learning and improvement: an educational resource from the ACGME outcome project. Online information available at http://www.acgme.org/outcome/implement/ complete_PBLIBooklet.pdf (accessed on July 21, 2007), 2005.

[7] Batalden PB, Stoltz PA-C. A framework for the continual improvement of health care: building and applying professional and improvement knowledge to test changes in daily work. Jt Comm J Qual Improv 1993; 19: 424-52.

[8] Bender AD, Motley RJ, Pierotti RJ, Bischof RO. Quality and outcomes management in the primary care practice. J Med Pract Mgt 1999; 14(5): 236-40.

[9] Schwarz M, Landis S, Rowe J. A team approach to quality improvement. Fam Pract Mgt 1999; 6(4): 25-32.

[10] Ogrinc G, Headrick LA, Morrison LJ, Foster T. Teaching and assessing resident competence in practice-based learning and improvement. J Gen Intern Med 2004; 19: 496-500.

[11] Institute for Healthcare Improvement. Online information available at http://www.ihi.org/ (accessed on November 19, 2007), 2007.

[12] Wong RY, Kassen BO, Hollohan K, Hatala R, Roberts JM. A new interactive forum to promote awareness and skills in quality improvement among internal medicine residents: a descriptive report. Can J Gen Int Med 2007; 2 (1): 35-36.

[13] Wong RY, Hollohan K, Roberts JM, Hatala R, Ma I, Kassen BO. A descriptive report of an innovative curriculum to teach quality improvement competencies to internal medicine residents. Can J Gen Int Med 2008; 3 (1): 26-9.

[14] Torre D, Daley B, Sebastian J, Elnicki M. Overview of current learning theories for medical educators. Am J Med 2006; 119(10): 903-7.

[15] Stasz C. Workplace skills in practice: case studies of technical work. Rand Corporation, 1996.

[16] Quick T. Successful team building. AMACOM Division American Management Association, 1992.

[17] Burnard P. Effective communication skills for health professionals. $2^{\text {nd }}$ ed. Nelson Thornes, 1997.

[18] Duffy FD, Gordon GH. Whelan G, Cole-Kelly K, Frankel R. Assessing competence in communication and interpersonal skills: the Kalamazoo II report. Acad Med 2004; 79 (6): 495-507.

[19] Kurtz S, Silverman J, Benson J, Draper J. Marrying content and process in clinical method teaching: Enhancing the CalgaryCambridge guides. Acad Med 2003; 78 (8): 802-9.

[20] Mincemoyer C, Thomson J. Establishing effective mentoring relationships for individual and organizational success. J Extension 1998; 36(2). Online information available at www.joe.org (accessed on December 12, 2007).

[21] Hewson M, Little M. Giving feedback in medical education. J Gen Intern Med 1998; 13: 111-16.

[22] Shortell S, Bennett C, Byck G. Assessing the impact of continuous quality improvement on clinical practice: What it will take to accelerate progress. Millbank Q 1998; 76(4): 593-624.

[23] Davidoff F, Batalden P. Toward stronger evidence on quality improvement. Draft publication guidelines: the beginning of a consensus project. Qual Saf Health Care 2005; 14: 319-25.

[24] Ladden D, Peters A, Kotch J, Fletcher R. Preparing faculty to teach managing care competencies: Lessons learned from a national faculty development program. Fam Med 2004; 36(Suppl): S115- 20. 